\title{
Understanding the determinants of Cloud Computing adoption in Saudi healthcare organisations
}

\author{
Fawaz Alharbi $^{1,2}$ - Anthony Atkins ${ }^{2}$ - Clare Stanier ${ }^{2}$
}

Received: 19 February 2016 / Accepted: 29 June 2016 / Published online: 13 July 2016

(c) The Author(s) 2016. This article is published with open access at Springerlink.com

\begin{abstract}
Cloud Computing is an evolving information technology paradigm that impacts many sectors in many countries. Although Cloud Computing is an emerging technology there is little in the literature concerning its application in the Saudi healthcare sector. This paper examines and identifies the factors that will influence the adoption of Cloud Computing in Saudi healthcare organisations. The study integrates the TOE (Technology-Organization-Environment) framework with the Information System Strategic Triangle (IS Triangle) and the HOT-fit (Human-OrganizationTechnology) model to provide a holistic evaluation of the determinants of Cloud Computing adoption in healthcare organisations. Of the five perspectives examined in this study, the Business perspective was found to be the most important followed by the Technology, Organisational and Environmental perspectives and finally the Human perspective. The findings of the study showed that the five most important factors influencing the adoption of Cloud Computing in this context are soft financial analysis, relative advantage, hard financial analysis, attitude toward change and pressure from partners in the business ecosystem. This study identifies the critical factors for both practitioners and academics that influence Cloud Computing adoption decision-making in Saudi healthcare.
\end{abstract}

Fawaz Alharbi

fawazharbi@gmail.com; fawaz.alharbi@ research.staffs.ac.uk

Anthony Atkins

a.s.atkins@staffs.ac.uk

Clare Stanier

c.stanier@staffs.ac.uk

1 Huraymila College of Science and Humanities, Shaqra University, Shaqraa, Saudi Arabia

2 School of Computing, Staffordshire University, Stafford, UK
Keywords Cloud Computing · Saudi Arabia $\cdot$ E-health · Healthcare $\cdot$ Strategic framework

\section{Introduction}

Healthcare services are facing many challenges in Saudi Arabia such as: the shortages of healthcare professionals, the increase of chronic diseases and the high cost of health services [1]. As a result, many healthcare organisations have implemented Information and Communication Technology (ICT), including e-health solutions, in their systems to provide better patient care, to enhance efficiency and to use their financial resources effectively. However, the adoption of e-health in Saudi healthcare organisations is still relatively low for many reasons [2]. Introducing IT systems in healthcare services is very expensive due to the higher cost in terms of Capital Expenditure (CAPEX) and Operational Expenditure (OPEX). The shortage of health informatics specialists and IT professionals is another obstacle to e-health projects [2]. The implementation of e-health solutions may also encounter technical difficulties such as complexity, compatibility and insufficient IT infrastructure [3]. Despite these barriers, Saudi healthcare facilities have demonstrated a willingness to implement and improve their e-health services. This creates a foundation for the use of new technologies and models that may move them forward such as the adoption of Cloud Computing.

Cloud Computing is a developing phenomenon in the ICT field that has gained increasing attention from healthcare organisations to overcome some of the e-health barriers [4]. Although there is no generally accepted definition of Cloud Computing [4,5], most of the definitions emphasise similar aspects $[5,6]$. Firstly Cloud Computing is a model of delivering IT services and resources not new technol-

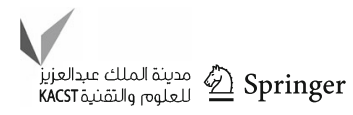


ogy. Secondly, the provisioning of resources is automatic and with a minimum of human interaction. Thirdly, access to the large pool resources is over a network. Fourthly, IT services and resources are available on demand with dynamic scalability and elasticity. The provisioning of IT resources should be independent of device and location (i.e. should have the characteristic of ubiquity). Finally, the use of IT resources in Cloud Computing requires a clear business model and clear measurement that typically uses OPEX payment methods [5]. Cloud Computing may assist in solving some of the management challenges of healthcare organisations in Saudi Arabia. Since financial issues are affecting e-health projects in the country, Cloud Computing can offer economic savings by decreasing the initial and operational costs of e-health projects in Saudi hospitals. Cloud Computing could help to reduce the problem of shortage of IT and health informatics technicians since the use of Cloud technology means that fewer technicians will be required by the healthcare organisations [7]. Cloudbased medical applications will also enable IT departments in healthcare organisations to focus more on supporting the implementation of e-health projects by moving some of their responsibilities to the Cloud providers' side particularly in a public Cloud Computing environment. For healthcare organisations, Cloud Computing will enable better integration and exchange of medical records across multiple organisations [8]. Using Cloud Computing in Saudi healthcare organisations will facilitate the provision of sufficient computing resources to deal with the large amount of data that is created by e-health services. This feature will also help Research and Development (R\&D) departments in healthcare organisation at the national level [8]. Cloud Computing used in collaboration with other technologies such as the Internet of Things, m-health and Big Data will help reshape healthcare services in Saudi Arabia. Cloud Computing solutions will be suitable technologies to be corresponding with Saudi healthcare future demands since the population of Saudi Arabia is expected to increase from $30 \mathrm{M}$ to $37 \mathrm{M}$ $\mathrm{m}$ by 2030 [9]. Cloud Computing technology will allow Saudi healthcare organisations to enhance their information processing capacity by sharing IT resources which include software, hardware, and expert skill sets. Cloud Computing could help in solving the fragmentation and isolation problem of healthcare information system in Saudi Arabia. Alharbi et al. in [10] proposed Saudi National E-health Cloud System (SNECS) that supports multi-stakeholders, multitechnologies and multi-applications environment. Elasticity feature of Cloud Computing which is the ability to scale the IT services dynamically and quickly could be appropriate for Saudi healthcare demands [5]. A potential use of this feature could be during Hajj session when Saudi Arabia hosts from 2 to 3 million people for specific time (i.e. 1-3 months) every year.
Very little academic research has addressed the Cloud Computing phenomenon in Saudi Arabia [11,12], and, in particular, none within the Saudi healthcare context. The aim of this research is to explore holistically the factors affecting Cloud Computing adoption in Saudi healthcare organisations. The results of this research study are expected to be valuable for both Cloud Computing providers and healthcare institutions by supporting the decision-making process of Cloud Computing adoption.

The structure of the paper is as follows: Sect. 2 provides a review of related work about the use of Cloud Computing in healthcare organisations and in Saudi Arabia. Section 3 describes the theoretical foundations of the research. Section 4 outlines the research framework and Sect. 5 presents the research methods. Section 6 shows the data analysis and Sect. 7 outlines the results. Section 8 discusses the findings of the study. Section 9 highlights the research contribution and Sect. 10 gives the conclusion and identifies areas for future work.

\section{Related work}

In healthcare, several studies have discussed Cloud Computing decision-making procedures [8]. Kuo in [4] recommended four aspects to be assessed when adopting health Cloud Computing: management, technology, security, and legal. Kuo also proposed a Healthcare Cloud Computing Strategic Planning (HC2SP) model. This model could serve as a SWOT analysis for health organisations to determine how to migrate from traditional health services to Cloud-based services. This model did not focus on the decision-making process. Lian et al. in [13] studied the decision to adopt Cloud Computing. They integrated Technology-Organisation-Environment (TOE) framework and Human-Organisation-Technology fit (HOT-fit) model to study the adoption of Cloud Computing in Taiwan. Their study indicated that the five most critical factors are: data security, perceived technical competence, costs, top management support, and complexity. This study focused on smalland medium-sized hospitals in Taiwan which have very high degree of e-healthcare maturity [13]. Hence, the result of this paper would not be generalised to developing countries. The study also did not discuss issues such as technology readiness, change resistance and the availability of external expertise. Rijnboutt et al. in [14] categorised the challenges facing the use of Cloud Computing in e-health services into six categories (technical, privacy, legal, organisational, economical and medical). However, this paper ignored environmental issues. Additionally, this model did not focus on the decision-making process.

Evaluating the existing frameworks for Cloud Computing decision-making, these frameworks are limited (i.e. they do not cover multiple perspectives). Current models and frame- 
works also focus mainly only on the operational and tactical level (i.e. ad hoc frameworks). Furthermore, while most of the frameworks are emphasising the technical side of Cloud Computing, they do not discuss other aspects such as business and organisational. There is also a lack of quantitative measures in the reviewed frameworks. The use of quantitative measures within the framework is important because they make the decision-making process more accurate and objective [15]. Although Low et al. in [16] pointed out that the influences of environmental and organisational factors on Cloud Computing adoption vary across different industry contexts, most of the frameworks are designed to be general and do not focus on specific sectors. Healthcare environments may vary across different countries. As a result, each country must be considered to be studied as individual case (i.e. private and public healthcare). Although some concepts of Cloud Computing will be generic, some of the concepts will be different due to the variation of the contexts and country requirements. For example, Cloud Computing applications in the USA must comply with Health Insurance Portability and Accountability Act (HIPAA) privacy and security rules in USA [17].

Cloud Computing in Saudi Arabia has not received much attention [12] and little research has been conducted in studying the implementation of Cloud Computing in the country. For example, Alharbi in [18] studied users' acceptance of Cloud Computing in Saudi Arabia based on Technology Acceptance Model (TAM). From an organisation level, Yamin in [12] completed a survey of Cloud Computing awareness in Saudi Arabia. The study showed that Cloud technologies will be a new trend for Saudi's organisations. However, this research provided a general view of Cloud Computing adoption in Saudi Arabia. Alkhater et al. in [11] investigated influential factors on the adoption decision of Cloud Computing in general. They indicated that many factors such as: trust, relative advantage, technology readiness will influence the use of Cloud Computing technology. However, they did not investigate the effect of two dimensions that are human and business on the implementation of Cloud Computing. Another limitation of their study is the sample size of the study which was small (i.e. 20 experts only). Tashkandi and Al-Jabri in [19] studied Cloud Computing adoption by higher education organisations in Saudi Arabia. The study focused on: technological, organisational and environmental factors. They found that relative advantage has positive influence on the decision of Cloud Computing adoption. They also found that complexity and vendor lock-in have negative influence on the decision of Cloud Computing adoption. Their study has some limitations such as: focusing mainly on higher education organisations and the researchers do not including business dimension which is important dimension in the adoption of Cloud Computing. Studying the adoption of Cloud Computing in Saudi Arabia in general (and in healthcare sector in particular) needs more investigative efforts $[11,12]$.

Healthcare environments may vary across different countries depending on cultural, social and technical characteristics. The financing of healthcare systems varies between countries. For example, in the UK and Australia general taxes are the main sources of healthcare system funding [20]. In other countries such as France, Germany and Japan, social insurance schema are the main source of funding for healthcare systems [20]. The role of the government is another factor that should be considered when making comparisons between different healthcare systems. While some governments act as regulator and insurer as in the Japanese healthcare system, other governments such as the New Zealand Government act as regulator, purchaser and provider of healthcare [20]. IT is also currently playing an important role in healthcare systems. While some countries have reached a high degree of e-health maturity, in other countries e-health is still an emerging discipline. For example, Taiwan started an e-healthcare program in 1995 [21], while Saudi Arabia launched the National E-health Strategy in 2011 [22]. Culture also plays an important role in healthcare systems around the world. A study found that social barriers such as language and resistance to the use of new systems affected EMR implementation in Saudi hospitals [23]. As a result, each country must be considered as individual cases.

Cloud Computing adoption also varies across countries and industries. Although researchers identify Cloud Computing as an IT global phenomenon, they also highlight that factors affecting Cloud Computing adoption play different roles across different economic environments. Legal factors such as data protection laws are different between countries even where the countries may be from the same region [5]. For example, although there is a compliance requirement for companies in the European Union (EU) with regard to data protection, wide variations exist at the national level for each member states of EU [24]. Government support of Cloud Computing also is different among countries. While some technologically advanced countries realised the potential benefits of Cloud Computing and launched Cloud Computing initiatives such as G-Cloud in UK and Kasumigaseki Cloud in Japan, other countries such as Saudi Arabia still have not yet undertaken a national Cloud Computing initiative. Cloud Computing research in the literature focuses mainly on technologically developed countries and fewer empirical studies have been conducted in developing countries $[25,26]$. Cultural and organisational characteristics may affect how different countries adopt Information Technology projects [27]. Examining the impact of cultural and organisational factors across different industries and countries represents a contribution to the body of knowledge about Cloud Computing adoption. 


\section{Theoretical framework}

Many researchers have recognised a need to use holistic and multidisciplinary approaches when studying or designing Health Information Technology (HIT) frameworks in healthcare $[28,29]$. The framework is designed to support the decision-makers in health organisations by covering multiperspectives. It is also designed in a flexible way to be adaptable to changing market conditions. The decision on adopting Cloud Computing is potentially a complex process and consequently there are many perspectives to be considered. Thus, studying this process requires a multi-perspective framework. The research framework will integrate more than one theoretical framework to make the suggested framework more robust and cover multi-aspects of the organisation. TOE has been chosen as a concept for this research together with Information System Strategic Triangle (IS Triangle) and HOT-fit. Figure 1 shows the relationship between HOT-fit, IS Triangle and TOE and the research framework.

\section{Technology-Organisation-Environment (TOE) framework}

Since Cloud Computing is an emerging approach to dealing with IT services [30], the appropriate framework is one which is aiming to study innovation decision-making at firm level. The Technology-Organisation-Environment (TOE) framework was introduced by Tornatzky et al. [31]. This framework focuses on the process by which a firm adopts and implements technological innovations and how the technological context, the organisational context, and the environmental context can affect the implementation of new innovation. Oliveira and Martins [32] suggested that the TOE framework is useful in studying the adoption decision-making process of different types of IT innovation.

TOE studies the adoption decision-making process at an organisation-level not at user-level which makes it relevant for this paper [5]. Many researchers have studied technology innovation based on TOE framework. Many examples could be mentioned here such as RFID adoption in the Healthcare environment [33], in web site development [34], in e-commerce [35], in Cloud Computing adoption by SMEs in England [36] and in Cloud Computing adoption by hospitals in Taiwan [13]. Although the TOE framework has been implemented by many researchers for different technology innovations, some researchers argue that the TOE framework does not contain all the variables in each context [16]. Hence, for new complex technology adoption such as Cloud Computing, more than one theoretical framework is required to express a better understanding of the adoption decision [16].

\section{Information systems strategy triangle}

Business concepts must be taken into consideration by any decision-maker [5]. Thus the strategic triangle will be combined with TOE framework to add the strategic value to the framework. The strategic triangle is a concept developed by [37] which emphasises the importance for organisations of having an alignment between three strategic perspectives (business, organisation and information). Some researchers consider Cloud Computing as an innovative form of traditional IT outsourcing [38]. This research will apply some of the concepts of a strategic framework for outsourcing decision-making that was called Holistic Approach Business, Information, and Organisation (HABIO). HABIO is a welldocumented framework used for outsourcing $[15,39,40]$.

\section{Human, Organisation and Technology-fit (HOT-fit) framework}

Human factors are also critical in the adoption of any new IT innovation. Those factors should be considered carefully when making the decision on adopting Cloud Computing in health environment [41]. Hence, Human, Organisation and Technology-fit (HOT-fit) framework will be integrated with previous frameworks. HOT-fit was introduced in [42] as an evaluation framework for health information systems. This research will apply some of the concepts of the (HOT-fit) model that relate to human perspective issues encountered by IT staff in healthcare organisations. The integration between HOT-fit and TOE has been implemented in studying the adoption of Cloud Computing in Taiwan hospitals [16].

\section{Research framework}

The research framework will be focused on five dimensions which are Organisation, Technology, Environment, Human and Business as identified in the chosen theoretical frameworks as illustrated in Fig. 1. The framework will help health organisations in the decision-making process by evaluating various factors affecting the Cloud Computing adoption. Migrating towards Cloud needs a multi-perspectives strategy that supports Cloud Computing capabilities [43]. This framework will try to help the health organisation in bridging the gap between their IT projects and providing better medical care with lower costs and high standards. The research framework is presented in Fig. 2.

\section{Technology context}

The technology dimension represents the technical issues that will affect the decision on Cloud Computing adoption. Health organisations which are intending to implement 


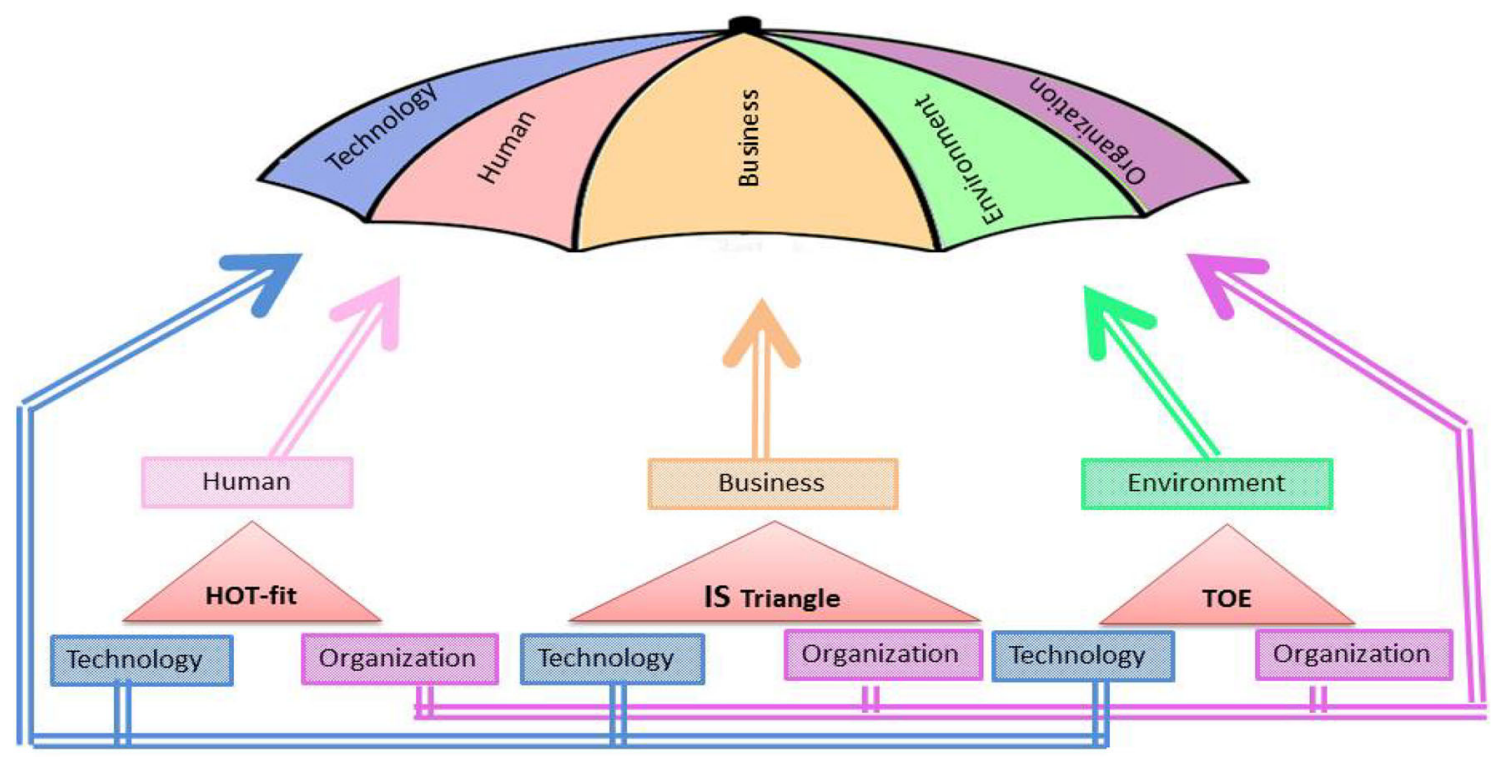

Fig. 1 The relation between HOT-fit, IS Triangle and TOE and the research framework

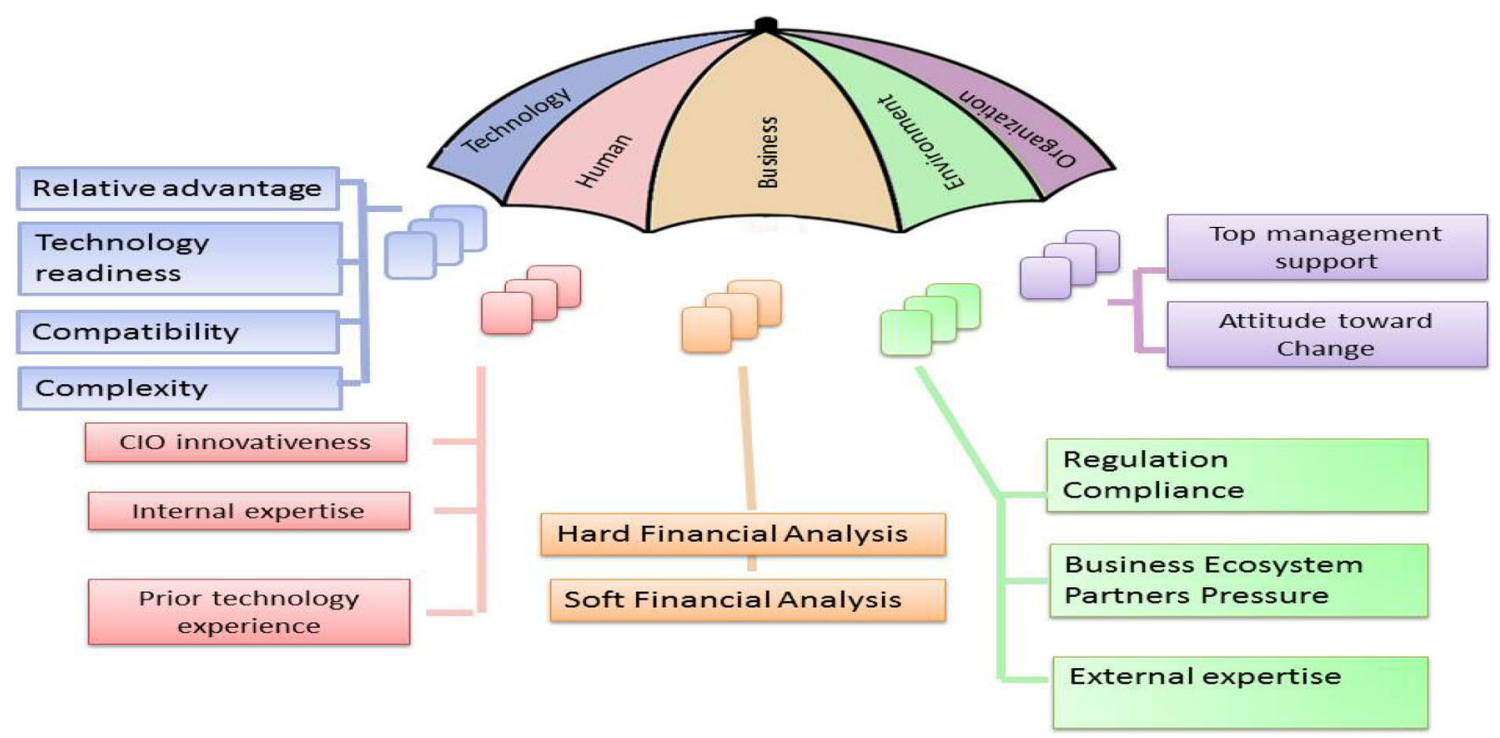

Fig. 2 The strategic framework for Cloud Computing decision-making in healthcare sector

Cloud Computing need to assess all information technology infrastructures of the organisations. Relative advantage factor refers to checking if the adoption of Cloud Computing technology will have clear benefits over other technologies for the specified health organisation. This factor is expected to be an important and positive significant factor for the decision of Cloud Computing adoption. Alharbi in [18] showed that perceived usefulness will positively affect users' attitude towards adopting Cloud Computing in Saudi organisations. Technology readiness could be an enabler factor of the decision of Cloud Computing adoption [44]. Issues connected with existing infrastructure can have a negative impact on the adoption of Cloud Computing, as outlined by a study on the adoption of health data standards in Saudi Arabia [3]. However, Cloud Computing can help in solving the problem of the availability of IT resources [8]. Saudi healthcare organisations require assessing key IT infrastructure indicators (i.e. software, hardware, network security, and Internet speed) before implementing Cloud Computing solutions $[24,45]$. E-health usually encompasses many health information systems. Thus, compatibility of Cloud Computing implementation with existing IT systems inside the health organisation should be another factor to be consider when adopting Cloud technology [46]. Some Saudi healthcare organisations found difficulty in making new systems compatible with current clinical systems [47]. 


\section{Organisational context}

The organisational factors also have their influences on the success or the failure of e-health projects. They are internal factors of an organisation that are controlled by the organisation itself. They play an important role in the decision-making process. Top management support can be a significant factor in Cloud adoption [36]. This factor refers to how executives identify the nature and functions of Cloud Computing technology and how this technology will affect the overall organisation [36]. Current research showed that employees in managerial positions in Saudi organisations had positive attitudes toward Cloud Computing adoption [18]. However, the situation in healthcare organisations may be different due to the nature of such organisations. The successful adoption of new technologies requires various changes to be made to the organisational structure, such change may face resistance from physicians, administrative and IT staffs [42]. Studies showed that resistance to the use of new systems is affecting Electronic Medical Record (EMR) implementation in hospitals in different countries $[23,48]$. This factor should be considered when adopting Cloud Computing solution in health organisation.

\section{Environmental context}

Environmental context refers to the different attributes of the external world in which the organisation conducts its business [13]. The use of Cloud Computing technologies in e-health will be affected by the relationship between different parties. Government legislation and policies can affect the decisions of healthcare firms trying to adopt new technology [42]. In the healthcare sector, data security and privacy protection are required not only by the patients themselves, but in most countries they are also required by law. Thus, data security is an essential factor that should be considered during any Cloud Computing implementation [46]. With the current security and privacy issues in the Cloud, this factor must be considered carefully. Although both Cloud Computing provider and healthcare organisation must comply with regulations that monitor security and data privacy issues, it is the healthcare organisation's responsibility to make sure that the provider applies reasonable security controls and has regulatory laws compliance [49]. For example, HIPPA regulations require American organisations to have a clause in their IT projects contracts confirming that the provider will follow specific security rules and processes [49]. Healthcare organisations have many partners such as: suppliers, vendors and government agencies that affect and are affected by each other. Thus, business ecosystem partners will influence the organisation decisions about implementing Cloud Computing solutions [50]. Additionally, most healthcare organisations rely on trading partners for their IT solutions so sufficient support from the Cloud vendors will be an influential factor affecting the decision of Cloud Computing adoption [16]. Instability of EMR vendors was found to be one of the barriers of EMR implementation in Saudi Hospitals [23]. Another factor that is associated with sufficient support from the vendor is the availability of external expertise [15]. E-health usually encompasses many health information systems and requires expertise from various domains such as medicine, IT and business processes. Additionally, the shortage of healthcare professionals is considered to be a challenge for the successful implementation of e-health projects in Saudi Arabia. Thus, the availability of healthcare-related expertise at Cloud Computing provider's side could be a factor which affects the decision on Cloud Computing adoption.

\section{Human context}

The human dimension should be considered before the implementation of any IT project as it is one of the factors that influence the adoption of an innovative technology [42]. Hospitals usually are slow in adopting new information technologies due to the decision-makers' characteristics [43]. Thus, the innovativeness of decision-makers or Chief Information Officer (CIO) innovativeness considerably influences the decision to adopt Cloud Computing [13]. Another factor which will affect the decision of Cloud Computing adoption is the capability of IT staff inside the hospital to deal with such technologies [13]. Insufficient technical knowledge can be considered as another barrier for e-health projects in general [48]. Thus, prior technology experience or the Cloud/IT skills of IT employees are also expected to impact the diffusion of Cloud Computing inside health organisations [51]. Human factors were identified as the main obstacles of successful implementation of EMR in Saudi healthcare organisations [2].

\section{Business context}

The business perspective refers to the consideration of business issues related to the adoption decision. The first factor is the hard financial issues regarding the implementation of Cloud Computing solutions. Hard financial analysis refers to financial analysis via the use of costing methods that utilise quantitative metrics [15]. The cost should be analysed in both capital expenditure (CAPEX) and operational expenditure (OPEX). The decision regarding which deployment models should be implemented also needs to be discussed carefully [14]. The organisation should have clear procurement strategies for Cloud Computing. Another factor that should be discussed is the strategic value that will be added to the health firm by using Cloud Computing technologies. This factor could be discussed through soft financial analysis which considers intangible aspects of Cloud Computing 
adoption decision [15]. Adopting Cloud Computing will give the possibility for new classes of applications and delivers services that were not possible before, such as mobile health, telemedicine and big data [8]. Another related issue is the impact of the adoption of Cloud Computing on medical and business processes [8]. The absence of implementation strategy has negatively affected e-health projects in Saudi Arabia [52]. It has been argued that the use of Cloud Computing will help the hospitals to move from the traditional healthcare model (doctor-centred model) to the new healthcare model (patient-centred model) by facilitating the sharing and access of patients' medical data and increasing patients' engagements [53].

\section{Research methods}

The aim of this research is to investigate the factors affecting Cloud Computing adoption in Saudi healthcare organisations. The literature demonstrates that limited academic research has addressed Cloud Computing phenomenon in Saudi Arabia [11,12], and, in particular, none within the Saudi healthcare context. Therefore, a questionnaire was developed to examine factors identified from the literature review (see Appendix for more details). The questionnaire consists of 44 questions and is divided into 5 parts. The first part acts as cover letter and consent form for the questionnaire. It also provides information about the study and the researcher. The second part is for demographic information such as: the role of the participant in the organisation, the type of the organisation, the size of the organisation. The third part is for Cloud Computing adoption status inside the organisations. The fourth part is for the different dimensions that could influence Cloud Computing adoption in healthcare organisations in Saudi Arabia. The questions in this part were measured on five-point Likert scale ranging from "strongly disagree" to "strongly agree". The final part was for additional comments by the participants. This study followed the questionnaire development process mentioned in [54] where the development of questionnaire is divided into three stages which are item construction, questionnaire reviewing process and questionnaire testing stage. For piloting the questionnaire, the questionnaire was distributed among two groups. The first group was healthcare professional group to make sure of clarity of the questionnaire. The second group was $\mathrm{PhD}$ students to have control on timing issues and to test usability of the online tool that has been used for distributing the questionnaire. At each stage, the recommendations were reviewed and the required changes were made before moving to the next stage.

Since adopting Cloud Computing will affect the whole organisation [55], the population of this study are all staff members in Saudi healthcare organisations which include IT staff, health professionals and administrative. Multiple stakeholders have been chosen for this study to emphasise the holistic approach that this study has adopted. Additionally, Alshammari in [56] found that $69 \%$ of managers in Ministry of Health MOH in Saudi Arabia are physicians or other allied health professionals. A Snowball approach was utilised to target employees of public and private healthcare organisations in Saudi Arabia. Snowball is a sampling technique that uses social chain referral to identify more participants [57]. Invitation letter and a link to the online questionnaire were distributed to 100 participants based on one of the authors' contacts in Saudi Arabia. The author also used his personal profiles on Twitter and LinkedIn to contact other participants. Participants were asked to participate and invite appropriate person in their organisations to participate. The invitation message was written in English and Arabic and included a brief about the research objectives.

An online questionnaire was used to collect the data. Qualtrics.com online tool was selected to design and develop the online questionnaire. An online questionnaire was chosen for this research because it provides some advantages for the researcher and the participants. For the participants, an online questionnaire can protect their privacy and give them the opportunity to participate in the questionnaire at their convenient time with enough time to understand the questions [58]. For the researcher, the advantages of using online surveys include saving time and money by easing data processing activities and eliminate the interviewer bias [59].

\section{Data analysis}

The goal of the study is to identify the factors that will affect Cloud Computing adoption in healthcare organisations in Saudi Arabia. After completing all the procedures for the questionnaire development, the questionnaire was distributed to the targeted audiences. 354 respondents were received during the period from $4 / 2 / 2015$ to $15 / 3 / 2015$. Although 206 respondents were returned completed, only 201 respondents were accepted for this study because 5 surveys were filled by participants who are not working in healthcare organisations. Therefore, the questionnaire response rate was $56.8 \%$.

All the online collected data was converted to Statistical Package for the Social Sciences (SPSS) format for analysis. Questionnaire was coded within SPSS version 22. In SPSS, each question in the questionnaire was typed as variable with coding option where applicable. Likert scale was coded from 1 to 5, with 1 represent 'Strongly Disagree', and 5 represents 'Strongly Agree'.

\section{Sample characteristics}

Table 1 represents the demographic characteristics of the participants. While more than half of the participants (56.6\%)

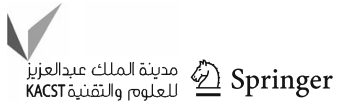


Table 1 The demographic characteristics of the participants

\begin{tabular}{|c|c|c|}
\hline Characteristics & Frequency & Percent $(\%)$ \\
\hline \multicolumn{3}{|l|}{ The role in the organisation } \\
\hline IT specialist & 57 & 28.4 \\
\hline Health professional & 114 & 56.6 \\
\hline Administrative & 18 & 9.0 \\
\hline Other & 12 & 6.0 \\
\hline \multicolumn{3}{|l|}{ Organisation type } \\
\hline $\begin{array}{l}\text { One of the Ministry of Health } \\
\text { organisations }\end{array}$ & 127 & 63.1 \\
\hline $\begin{array}{l}\text { Another governmental health } \\
\text { organisation (e.g. NGHA, } \\
\text { military hospitals, etc.) }\end{array}$ & 59 & 29.4 \\
\hline Private healthcare organisation & 15 & 7.5 \\
\hline \multicolumn{3}{|l|}{ Organisation location } \\
\hline Central Province & 114 & 56.6 \\
\hline Western Province & 59 & 29.4 \\
\hline Eastern Province & 9 & 4.5 \\
\hline Southern Province & 6 & 3.0 \\
\hline Northern Province & 13 & 6.5 \\
\hline \multicolumn{3}{|l|}{ Organisation size } \\
\hline Less than 50 employees & 24 & 11.9 \\
\hline 50-500 employees & 51 & 25.4 \\
\hline More than 500 employees & 117 & 58.2 \\
\hline I do not know & 9 & 4.5 \\
\hline \multicolumn{3}{|l|}{ Participants experience } \\
\hline Less than 2 years & 32 & 15.9 \\
\hline Between 2 and 5 years & 52 & 25.9 \\
\hline Between 5 and 10 years & 50 & 24.9 \\
\hline More than 10 years & 67 & 33.3 \\
\hline
\end{tabular}

are health professionals such as doctors, nurses, pharmacist, $28.4 \%$ of the participants are working as IT specialists in healthcare organisations. The other participants are from administrative staff or related area. This is similar to the real distribution in Saudi healthcare organisations where health professionals are the majority of human resources in healthcare organisations [60]. 58.2\% of the participants have more than 5 years' experience in healthcare area and $41.8 \%$ have less than 5 years' experience in healthcare area.

The majority of the respondents are from Ministry of Health (MOH) in Saudi Arabia (63\%). The other participants (29\%) are from other governmental health organisations such as military hospitals and National Guard Health Affairs (NGHA). Only $8 \%$ are working at private health organisations. This is close to the real situation of healthcare organisations in Saudi Arabia. $60 \%$ of health organisations in Saudi Arabia are $\mathrm{MOH}$ organisations, $30 \%$ are other governmental health organisations and only $10 \%$ are private organisations [60].
Regarding the size of the organisations, $58.2 \%$ of the participants are in large organisations that have more than 500 employees. Only $37.3 \%$ of the respondents are in small- and medium-sized organisations. $4.5 \%$ of the respondents said they do not know about the size of their organisations.

There are five provinces in Saudi Arabia and the geographical distribution for the participants is as follows: Central Province $(56.7 \%)$, Western Province $(29.4 \%)$, Eastern Province $(4.5 \%)$, Western region $(3.0 \%)$ and Northern region $(6.5 \%)$. This indicates that most of the participants are working in Central and Western province which is expected since most of the main offices of the healthcare organisations in Saudi Arabia are located in those two regions and they have the majority of Saudi population [60].

\section{Validity and reliability}

Reliability of the questionnaire is measuring the degree of internal consistency between the variables each construct [61]. Cronbach alpha test was conducted on the items of each construct to test the validity of the questionnaire and its internal consistency [57]. While Cronbach's alpha value ranges between one (perfect reliable) and zero (unreliable), values greater than 0.5 are considered to be acceptable [62]. All Cronbach's alpha values of the constructs of this research are greater than 0.5 except complexity. Therefore, the researcher decided to remove it from the research model since some of its component will be covered by other constructors. Table 2 shows construct reliability of all items.

Table 2 Construct reliability of all items

\begin{tabular}{lll}
\hline Construct & $\begin{array}{l}\text { Number } \\
\text { of items }\end{array}$ & $\begin{array}{l}\text { Cronbach's } \\
\text { alpha }\end{array}$ \\
\hline Relative advantage & 3 & 0.800 \\
Technology readiness & 3 & 0.741 \\
Compatibility & 3 & 0.720 \\
Complexity & 2 & 0.246 \\
CIO innovativeness & 2 & 0.907 \\
Internal expertise & 2 & 0.692 \\
Prior technology experience & 2 & 0.713 \\
Top management support & 2 & 0.838 \\
Attitude toward change & 2 & 0.847 \\
Regulation compliance & 3 & 0.678 \\
Business ecosystem partners & 3 & 0.600 \\
pressure & & \\
External expertise & 2 & 0.593 \\
Hard financial analysis & 3 & 0.608 \\
Soft financial analysis & 3 & 0.773 \\
\hline
\end{tabular}


Table 3 Validity of instrument items

\begin{tabular}{|c|c|c|c|c|c|c|c|c|c|c|c|c|c|}
\hline \multirow[t]{2}{*}{ K/B/TVE } & \multicolumn{2}{|c|}{$\begin{array}{l}\text { B } \\
0.79 / 0.00 / 50.35 \%\end{array}$} & \multicolumn{3}{|c|}{$\begin{array}{l}\mathrm{T} \\
0.82 / 0.00 / 57.20 \%\end{array}$} & \multicolumn{2}{|c|}{$\begin{array}{l}\mathrm{O} \\
0.72 / 0.00 / 69.77 \%\end{array}$} & \multicolumn{3}{|c|}{$\begin{array}{l}\mathrm{E} \\
0.77 / 0.000 / 58.00 \% \\
\end{array}$} & \multicolumn{3}{|c|}{$\begin{array}{l}\mathrm{H} \\
0.76 / 0.000 / 58.93 \%\end{array}$} \\
\hline & HA & SA & RA & TR & $\mathrm{CO}$ & $\mathrm{TS}$ & $\mathrm{CR}$ & $\mathrm{RC}$ & $\mathrm{TP}$ & $\mathrm{EE}$ & CI & IE & $\mathrm{PE}$ \\
\hline B1 & 0.534 & & & & & & & & & & & & \\
\hline B2 & 0.643 & & & & & & & & & & & & \\
\hline B3 & 0.738 & & & & & & & & & & & & \\
\hline B4 & & 0.710 & & & & & & & & & & & \\
\hline B5 & & 0.793 & & & & & & & & & & & \\
\hline B6 & & 0.803 & & & & & & & & & & & \\
\hline $\mathrm{T} 1$ & & & 0.589 & & & & & & & & & & \\
\hline $\mathrm{T} 2$ & & & 0.548 & & & & & & & & & & \\
\hline $\mathrm{T} 3$ & & & 0.529 & & & & & & & & & & \\
\hline $\mathrm{T} 4$ & & & & 0.591 & & & & & & & & & \\
\hline T5 & & & & 0.672 & & & & & & & & & \\
\hline T6 & & & & 0.612 & & & & & & & & & \\
\hline $\mathrm{T} 7$ & & & & & 0.675 & & & & & & & & \\
\hline $\mathrm{T} 8$ & & & & & 0.73 & & & & & & & & \\
\hline T9 & & & & & 0.668 & & & & & & & & \\
\hline $\mathrm{O} 1$ & & & & & & 0.798 & & & & & & & \\
\hline $\mathrm{O} 2$ & & & & & & 0.865 & & & & & & & \\
\hline $\mathrm{O} 3$ & & & & & & & 0.858 & & & & & & \\
\hline $\mathrm{O} 4$ & & & & & & & 0.819 & & & & & & \\
\hline E1 & & & & & & & & 0.682 & & & & & \\
\hline E2 & & & & & & & & 0.711 & & & & & \\
\hline E3 & & & & & & & & 0.554 & & & & & \\
\hline E4 & & & & & & & & & 0.637 & & & & \\
\hline E5 & & & & & & & & & 0.590 & & & & \\
\hline E6 & & & & & & & & & 0.661 & & & & \\
\hline E7 & & & & & & & & & & 0.671 & & & \\
\hline E8 & & & & & & & & & & 0.721 & & & \\
\hline H1 & & & & & & & & & & & 0.825 & & \\
\hline $\mathrm{H} 2$ & & & & & & & & & & & 0.818 & & \\
\hline $\mathrm{H} 3$ & & & & & & & & & & & & 0.780 & \\
\hline $\mathrm{H} 4$ & & & & & & & & & & & & 0.695 & \\
\hline H5 & & & & & & & & & & & & & 0.750 \\
\hline H6 & & & & & & & & & & & & & 0.729 \\
\hline
\end{tabular}

$B$ business, $T$ technology, $O$ organisation, $E$ environment, $H$ human, $K$ KMO test, $B$ Bartlett's test, $T V E$ total variance explained

Factor analysis was implemented to determine the instrument construct validity. All items in the instrument have to meet the following criteria: the threshold of factor loading is 0.5 and eigenvalue is larger than 1.

As a result, 13 factors are extracted from the five contexts (see Table 3). The variables are labelled and abbreviated as follows: HA, hard financial analysis; SA, soft financial analysis; RA, relative advantage; TR, technology readiness; $\mathrm{CO}$, compatibility; TS, top management support; $\mathrm{CR}$, attitude toward change; RC, regulation compliance; TP, business ecosystem partners pressure; $\mathrm{EE}$, external expertise; CI, CIO innovativeness; IE, internal expertise; PE, prior technology experience.

\section{Cloud Computing adoption}

In this paper, Cloud Computing adoption refers to the extent of Cloud Computing adoption status in Saudi healthcare organisations. The approach taken by Haddad et al. [44] and Lian et al. [13] was adopted to measure Cloud Computing 
adoption status. This item is a category scale in the questionnaire and responses to this question were classified as follows:

- I do not know.

- We have already adopted some Cloud Computing services.

- We intend to adopt Cloud Computing services in the next 2 years.

- We do not intend to adopt any Cloud Computing services for the foreseeable future.

The option (do not know) was used as an indicator to ascertain the amount of staff engagement in the organisation concerning the Cloud Computing adoption decision-making process. Among the participants, only $36.8 \%$ participants reported that their organisations have adopted some Cloud Computing services. Software as a service ( $\mathrm{SaaS}$ ) is the dominant service model where about $84 \%$ of the organisations have adopted some types of this model. This percentage of Cloud Computing adoption rate is similar to the percentage in Taiwan where $35 \%$ of the hospitals using Cloud Computing solutions [13]. However, it is still low when it is compared with the adoption of Cloud Computing services among American healthcare organisations with $80 \%$ [63]. Figure 3 presents the organisation's plan for Cloud Computing adoption among Saudi healthcare organisations.

\section{Overall findings}

The goal of this research is to identify factors that influence the adoption of Cloud Computing in Saudi Arabia's healthcare organisations. The authors have accomplished this by analysing the data collected from the survey. Among the five dimensions, the most important one is Business (mean 3.90), then Technology (mean 3.62), followed by Organisational (mean 3.49), Environmental (mean 3.47), and finally Human (mean 3.36); see Table 4 for analysis of factors affecting

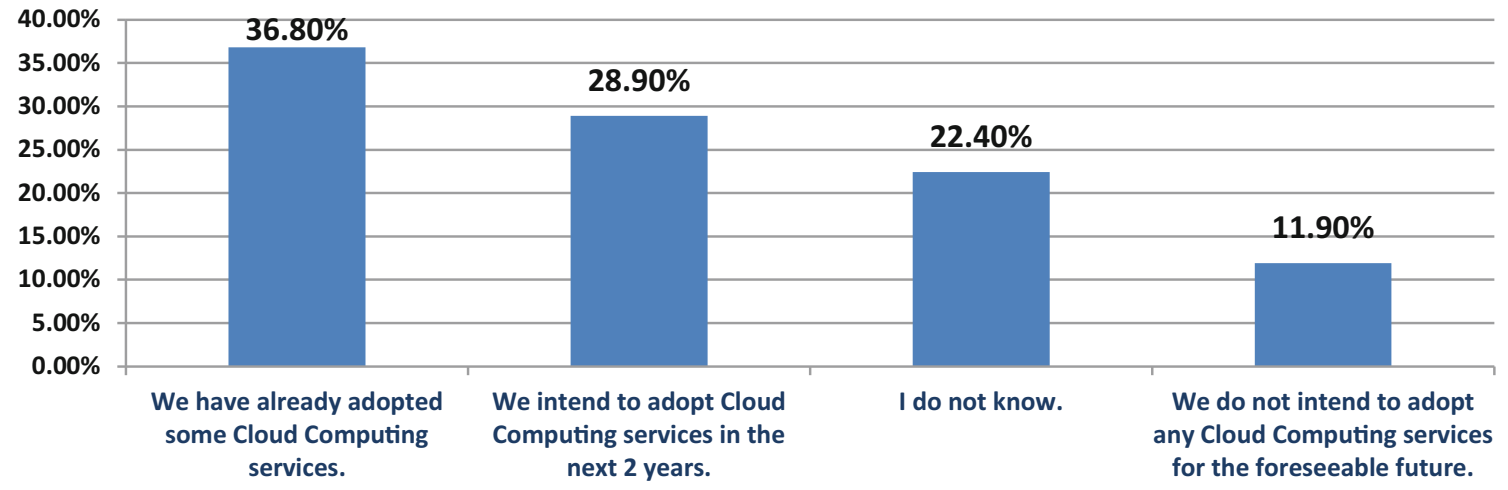

Fig. 3 Organisation's plan for Cloud Computing adoption among Saudi healthcare organisations

Table 4 Analysis of factors affecting Cloud Computing adoption in Saudi healthcare organisations

\begin{tabular}{lllll}
\hline Context & Variables & Mean & S.D & Rank \\
\hline Business 3.90/ 1 & Soft financial analysis & 3.99 & 0.907 & 1 \\
& Hard financial analysis & 3.81 & 0.918 & 3 \\
Technology 3.62/2 & Relative advantage & 3.93 & 0.958 & 2 \\
& Compatibility & 3.47 & 1.016 & 7 \\
& Technology readiness & 3.46 & 1.154 & 8 \\
Organisational 3.49/3 & Attitude toward change & 3.65 & 1.057 & 4 \\
& Top management support & 3.32 & 1.284 & 12 \\
Environmental 3.43/4 & Business ecosystem partners pressure & 3.52 & .952 & 5 \\
& External expertise & 3.49 & .969 & 6 \\
Human 3.36/ 5 & Regulation compliance & 3.29 & 1.139 & 13 \\
& Internal expertise & 3.40 & 1.064 & 9 \\
& CIO innovativeness & 3.36 & 1.294 & 10 \\
& Prior technology experience & 3.33 & 1.035 & 11 \\
\hline
\end{tabular}




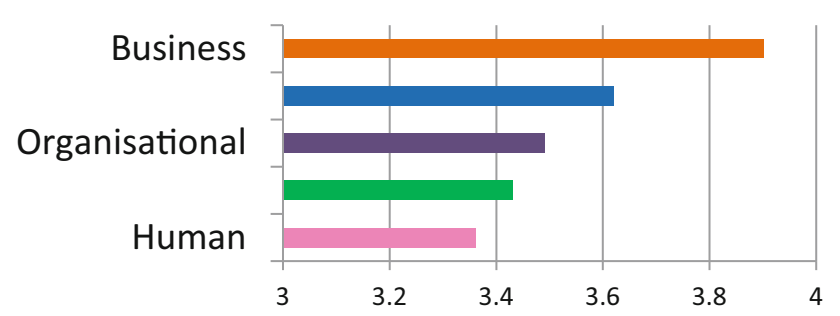

Fig. 4 Ranking the overall contexts affecting Cloud Computing adoption in Saudi healthcare organisations

Cloud Computing adoption in Saudi healthcare organisations.

The results show that five most critical factors affecting the decision of Cloud Computing adoption in Saudi healthcare organisations are: soft financial analysis, relative advantage, hard financial analysis, attitude toward change and business ecosystem partners' pressure. Figure 4 also represents another view of the overall results.

\section{Comparison between different groups}

The result of the questionnaire showed that Saudi healthcare organisations are divided into three categories. The first category is the organisations that have already adopted some Cloud Computing solutions. The second category is the organisations that are planning to adopt Cloud Computing. The third category is the organisations that do not intend to adopt any Cloud Computing services for the foreseeable future. The researchers used analysis of variance (ANOVA) test to find any useful information that explain the difference between the three categories then they will be implemented in the research framework. ANOVA is a statistical test that assesses the means between the groups that the authors are interested in and examines whether any of those means are significantly different from each other [57]. Table 5 shows the mean for the different categories based on organisations adoption status for all constructors. The results showed that there are significant differences in 7 factors which are RA, relative advantage ( $p=0.017)$; CO, compatibility $(p=0.002)$; $\mathrm{CR}$, attitude toward change ( $p=0.011)$; TS, top management support ( $p=0.007)$; CIO innovativeness $(p=0.038)$; IE, internal expertise $(p=0.003)$; PE, prior technology experience $(p=0.015)$. The major differences in RA are between planning to adopt group (mean 4.16) and rejecter (mean 3.69). For $\mathrm{CO}$, the major differences are among adopter (mean 3.73) and rejecter (mean 3.18). For CR and TS, the major differences exist between the adopter group and other groups. The differences have been found to be significant in IE, CI and between the adopter group and other groups. Among the five contexts, there was a significant difference in technology $(p=0.021)$ and organisational $(p=0.023)$. In technology context, the major differences are between adopter (mean 3.80) and rejecter (mean 3.43). In organisational dimension, the major differences exist between adopter (mean 3.89) and rejecter (mean 2.73) and between planning to adopt group (mean 3.36) and rejecter (mean 2.73).
Table 5 Variables across different groups

\begin{tabular}{|c|c|c|c|c|c|c|c|}
\hline \multirow[t]{2}{*}{ Context } & \multirow[t]{2}{*}{ Constructor } & \multicolumn{2}{|c|}{ Adopter } & \multicolumn{2}{|c|}{$\underline{\text { Planning to adopt }}$} & \multicolumn{2}{|c|}{$\underline{\text { Rejecter }}$} \\
\hline & & Mean & $\mathrm{SD}$ & Mean & $\mathrm{SD}$ & Mean & $\mathrm{SD}$ \\
\hline \multirow[t]{2}{*}{ Business } & SA & 4.02 & 0.732 & 4.07 & 0.809 & 3.79 & 0.850 \\
\hline & HA & 3.83 & 0.681 & 3.89 & 0.732 & 3.69 & 0.673 \\
\hline \multirow[t]{3}{*}{ Technology } & $\mathrm{RA}^{* *}$ & 3.91 & 0.749 & 4.16 & 0.901 & 3.69 & 0.804 \\
\hline & $\mathrm{CO}^{* *}$ & 3.73 & 0.700 & 3.49 & 0.937 & 3.18 & 0.997 \\
\hline & TR & 3.75 & 0.764 & 3.44 & 0.982 & 3.14 & 0.529 \\
\hline \multirow[t]{2}{*}{ Organisational } & $\mathrm{CR}^{* *}$ & 3.95 & 0.918 & 3.64 & 1.029 & 2.98 & 0.972 \\
\hline & $\mathrm{TS}^{* *}$ & 3.83 & 1.120 & 3.09 & 1.218 & 2.48 & 1.078 \\
\hline \multirow[t]{3}{*}{ Environmental } & $\mathrm{TP}$ & 3.64 & 0.627 & 3.54 & 0.702 & 3.08 & 0.800 \\
\hline & $\mathrm{EE}$ & 3.53 & 0.927 & 3.49 & 0.814 & 3.13 & 0.912 \\
\hline & $\mathrm{RC}$ & 3.44 & 0.903 & 3.33 & 0.899 & 2.83 & 0.927 \\
\hline \multirow[t]{8}{*}{ Human } & $\mathrm{IE}^{* *}$ & 3.64 & 0.909 & 3.40 & 0.912 & 3.23 & 0.821 \\
\hline & $\mathrm{CI}^{* *}$ & 3.78 & 1.107 & 3.21 & 1.246 & 2.92 & 1.283 \\
\hline & $\mathrm{PE}^{* *}$ & 3.66 & 0.836 & 3.14 & 0.821 & 3.02 & 1.118 \\
\hline & Business & 3.93 & 0.645 & 3.98 & 0.684 & 3.74 & 0.654 \\
\hline & Technology** & 3.80 & 0.523 & 3.70 & 0.772 & 3.34 & 0.491 \\
\hline & Organisational** & 3.89 & 0.905 & 3.36 & 1.021 & 2.73 & 0.853 \\
\hline & Environmental & 3.56 & 0.626 & 3.49 & 0.630 & 3.10 & 0.660 \\
\hline & Human & 3.69 & 0.789 & 3.25 & 0.814 & 3.06 & 0.953 \\
\hline
\end{tabular}

$* * p<0.05$ 


\section{Discussion}

\section{Business context}

The business context represents the consideration of business issues related to the adoption decision. The results show that business context is the most important context among the five contexts. Both factors (i.e. soft financial analysis and hard financial analysis) in this context have high values which represent the importance of business concerns on the adoption decision. Since Cloud Computing is a new way of delivering and dealing with computing services not a new technology [64], many healthcare organisations evaluate the use of Cloud Computing from a strategic point view. This has been shown by making soft financial analysis as the most important factor among other factors. This can be supported by the finding of [65] where the researcher found that perceived benefits has positive impact on Cloud adoption decision. The perceived benefits of Cloud Computing may go beyond cost savings such as providing new services that could not be provided before [64]. Awosan in [66] found that increased focus on core business is a major reason for adopting the Cloud. However, other researchers found that critical business processes are negatively affected by Cloud adoption [26]. Another important variable in this context is the hard financial analysis where the cost of Cloud Computing solutions is considered. Cost effectiveness has a positive and significant effect on the decision to adopt the Cloud Computing in many studies $[13,44]$. This result is expected since cost saving is one of the main drivers of Cloud Computing adoption. However, organisations should be careful of the hidden costs of Cloud Computing [26,67]. Another finding of the current study is that there are no significant differences that exist between the different categories for all factors in business context. This may indicate that healthcare organisations in Saudi Arabia believe in the importance of considering intangible and tangible effects of using Cloud Computing.

\section{Technology context}

The technology context refers to the technical issues that will affect the decision of Cloud Computing adoption. This dimension is the second most important dimension. The relative advantages of Cloud Computing over traditional IT has been seen as an important factor for healthcare organisations. Thus, relative advantage was identified as second important factor in this study. This finding can be supported by other researchers who indicated that the greater the relative advantage to the organisation, the more willingness it will have to adopt Cloud Computing $[16,19,44,68]$. Relative advantages of Cloud Computing will be seen in elements in addition to cost savings such as faster implementation time [69]. Com- patibility and technology readiness were behind other factors (7th and 8th), respectively. However, their alignment was toward the generally agreed category where the mean of compatibility is 3.47 and the mean of technology readiness is 3.46. With regard to compatibility, it has been suggested that some organisations may have concerns about the compatibility of Cloud Computing with the organisations' information systems $[68,70]$. Compatibility has been found to not have significant effect on Cloud Computing adoption in Saudi's academic organisations [19]. Other researchers found that compatibility has a positive impact on the Cloud Computing adoption decision in the services sector in Portugal [44]. One reason for this may relate to the organisation's decision priorities (i.e. cost or business processes) [68]. Variations in organisations' cultures and policies could be another reason [70]. Technology readiness was found to not necessarily influence Cloud Computing adoption or have negative impact on the adoption decision in some studies $[16,70,71]$. However, some studies indicated that technology readiness is a facilitator of Cloud Computing adoption [44]. One reason for this again refers to the variations in organisations IT infrastructure. Also organisations that intend to or have adopted Cloud Computing solutions have already made or will make some amendments over their infrastructure [16]. Changing security mechanisms could be an example of such required amendment [72]. This study shows that the relative advantage factor is more important for planning to adopt than for adopting. However, the adopter group could be faster in implementing Cloud Computing solutions because of other factors such as the availability of IS human resources and CIO innovativeness. Compatibility variable is also assessed as more important by adopters. This is expected since they are considered as innovators which are dealing with immature technologies such as Cloud Computing [16,19].

\section{Organisational context}

Organisational factors are the internal factors of an organisation that are controlled by the organisation itself [68]. While the organisational dimension is the a second most important dimension for adopter group, it is the least important dimension for the rejecter group. Both factors in this context present significant differences across different adopting groups. One factor of this dimension comes at 4th ranking among other factors which is 'Attitude toward Change'. The attitude toward Cloud Computing in Saudi Arabia in the current study is positive which consistent with other research which indicated that employees in managerial positions in Saudi organisations had positive attitudes toward Cloud Computing adoption [18]. However, other studies showed that Cloud Computing may face some resistance among the employees in institutions in different countries $[69,73]$. One source of 
resistance to change could be from IT managers who are afraid of losing control of their IT sources [69]. Top management support plays a significant role in Cloud Computing adoption. Some empirical researches have shown that there is a positive relationship between top management support and adoption of Cloud Computing [13,16,36]. However, the result of this study indicated that healthcare top managers are in a neutral position about Cloud Computing adoption. This result is consistent with another study about Cloud Computing in Saudi's academic organisations [19]. Two reasons could be given to explain this result. The first reason is the immaturity of Cloud Computing services in Saudi Arabia $[12,19]$. Secondly, some healthcare organisations' mangers may still have some concerns about the hidden costs of Cloud Computing or about data security and privacy. This study also shows that attitude toward change and top management support are more important for adopter organisations than hard financial analysis. Thus, this study also offers empirical evidence that top management support attitude toward change will play important role in the decision of adopting Cloud Computing.

\section{Environmental context}

Environmental factors are related to the external world in which the organisation conducts its business. In this study, three factors were considered which are regulation compliance, business ecosystem partners' pressure and external expertise. Only one factor comes as one of the five most critical factors affecting the decision of Cloud Computing adoption in Saudi healthcare organisations which is business ecosystem partners' pressure (mean 3.58). Healthcare organisations have many partners such as: suppliers, vendors and government agencies that affect and are affected by each other. External pressure has been found to be positively related with Cloud Computing adoption in many researches $[19,36,74]$. External pressure from (e.g. IT vendors) could be influential or in the case of governmental regulation could be compulsory [16]. Another related factor is the availability of external expertise that would support the healthcare institutes in adopting Cloud Computing solutions. This factor ranked as 6th among the factors. IT providers with good capabilities of support and reputation could influence the organisations' innovation adoption decision. The importance of the availability of external expertise is supported by other studies [26,36]. It was also found that the lack of trust in Cloud services providers has negative impact on Cloud Computing adoption in other countries [66]. In this study, government legislation and policies have not been found to have high influence on Cloud Computing adoption in Saudi healthcare organisations. Other researchers $[19,44,51]$ have indicated that regulation compliance is not a determinant of
Cloud Computing adoption. It has been suggested that sector specific regulations may have negative influence on the decision of adopting Cloud Computing in healthcare environment [26]. There are two possible explanations for the finding of this study. The first one is that it is mandatory for healthcare organisations to follow compliance requirements so they do not need to consider it when making their decision about Cloud Computing [51]. The second reason may refer to the lack of regulations in Saudi Arabia regarding Cloud Computing services $[19,44]$. However, Saudi healthcare organisations considering Cloud Computing adoption must take into account the fact that they must comply with all IT regulations in Saudi Arabia such as Computing and Networking Controls in Government Agencies Act. Additionally, healthcare organisations in Saudi Arabia must ensure that providers will apply specific security measurements and standards such as ISO/IEC 27002 and ISO/IEC 27001 standards [75]. Healthcare organisations also should include security requirements in their Service Level Agreements (SLA) or any other legal agreements [49].This study shows that there is no significant difference between different groups for all factors in environmental context. A possible explanation is that Cloud Computing adoption decisions in Saudi healthcare organisations rely more on the internal needs and capabilities of the organisation rather than external pressure.

\section{Human context}

The human context was found to be less important dimension than the other dimensions. This finding is not consistent with another study [13] where the human dimension was found to be the second most important dimension among four different dimensions. All the factors in human context in the present study are found to be in a neutral position as following: internal expertise (mean 3.40), CIO innovativeness (mean 3.36) and prior technology experience (mean 3.33). Although the availability of internal IS expertise was found to be one of the most important factors that affects the decision on the adoption of Cloud solutions in Taiwanese hospitals [13], this is not the case in Saudi healthcare institutions. The dependence of Saudi healthcare organisations on trading partners for their IT solutions could offer an explanation for this result. Another explanation for this may refer to the fear of downsizing of IT department staff [66]. The CIO innovativeness factor is not influencing Cloud Computing adoption decision in Saudi healthcare organisations. This finding is consistent with another study about Taiwanese hospitals [13]. This result is expected since hospitals usually are slow in adopting new information technologies due to the decision-makers' characteristics [43]. In this study, prior technology experience of Cloud Computing has not been found to have high influence on Cloud Computing adoption

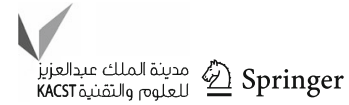


in Saudi healthcare institutions. This may refer to the fact that the use of Cloud Computing is still developing in the healthcare field. Some researchers indicated that lack of knowledge on Cloud Computing negatively affects Cloud Computing adoption [26]. Although, all the factors in this context are found to be in neutral positions, the differences have been found to be statistically significant for all factors. This finding shows that healthcare organisations that are more open for new ideas are more likely to adopt Cloud Computing faster than the others. It also indicates that healthcare organisations in Saudi Arabia should complete an assessment of their internal capabilities before taking the decision on Cloud Computing adoption.

\section{Research contribution and implication}

For academia, this study makes important contributions to the body of research on the adoption of Cloud Computing. The initial literature review showed that there is limited empirical research about the factors that have an impact on the adoption of Cloud Computing in Saudi Arabia [11,12] and, in particular, none within the Saudi healthcare context. Thus, the first contribution of this research is to study the factors that will affect Cloud Computing adoption in Saudi healthcare organisations. To the best of our knowledge, this study is among the first exploratory studies that addresses the Cloud Computing in healthcare organisations in Saudi Arabia. This research adopts a holistic view to build a framework that covers multiple perspectives so it in addition to the technology perspective it includes Human, Business, Organisational and Environmental factors. Our research combines different theoretical frameworks to provide a holistic assessment of the determinants of Cloud Computing adoption in Saudi healthcare organisations.

For practitioners, this study presents several key findings and organisations about the determinants of Cloud Computing adoption in the healthcare organisations in Saudi Arabia. Firstly, the obtained results indicate that the five most critical factors are soft financial analysis, relative advantage, hard financial analysis, attitude toward change and business ecosystem partners' pressure. Secondly, the decision on the adoption of Cloud Computing in Saudi healthcare organisations is mainly a business decision not a technology decision. This can be demonstrated by the finding that business factors are among the most important factors that affect the decision on Cloud Computing adoption. The findings of this study indicate that significant differences exist in relative advantage, compatibility, attitude toward change, top manager support, CIO innovativeness, internal expertise, prior technology experience across different adopting groups. Thus, this research highlights the importance of human and organisational attributes on organisations' intention toward adopting Cloud Computing.

\section{Conclusion}

Cloud Computing offers several benefits for Saudi healthcare organisations such as economic savings, reduction of shortages in health informatics, more collaboration between healthcare facilities. However, Cloud Computing is still not well covered by researchers in Saudi Arabia. To the best of the authors' knowledge, this research is among the earliest researches that addresses the Cloud Computing phenomena in Saudi healthcare context. Thus, this research fills a gap related to understanding the adoption of Cloud Computing services in the healthcare environment. It also studied the factors that may influence an organisation's intention to adopt Cloud Computing from holistic view. This study could be implemented as an assessment tool for healthcare organisations intending to adopt Cloud Computing. The major limitation of this study is that the sample is limited to the country of Saudi Arabia. Although a larger sample size may be required for the generalisation of the results, the findings provide a valuable insight into the factors which should be considered when adopting Cloud Computing in healthcare organisations. The framework was developed for use in Saudi Arabia context, but is based on a theoretical foundation which would allow the framework to be adapted for use in other contexts and environments. The factors used in the framework could be adapted to include factors specific to different countries. Security and privacy issues may require further investigation in future work for Cloud Computing adoption in Saudi healthcare organisations. It would be interesting to carry out further studies in other countries that are similar to Saudi Arabia such as Arabic gulf countries. The future work of this research is to apply the case study approach to provide in-depth understanding of Cloud Computing adoption decision-making in healthcare organisations in Saudi Arabia.

Open Access This article is distributed under the terms of the Creative Commons Attribution 4.0 International License (http://creativecomm ons.org/licenses/by/4.0/), which permits unrestricted use, distribution, and reproduction in any medium, provided you give appropriate credit to the original author(s) and the source, provide a link to the Creative Commons license, and indicate if changes were made. 


\section{Appendix: Measurement items}

\begin{tabular}{|c|c|c|c|}
\hline \multirow{2}{*}{$\begin{array}{l}\text { Constructs } \\
\text { Relative advantage }\end{array}$} & \multicolumn{2}{|c|}{ Items } & \multirow{2}{*}{$\frac{\text { Adapted source }}{[44,68]}$} \\
\hline & $\mathrm{T} 1$ & $\begin{array}{l}\text { Cloud Computing will allow my organisation to accomplish specific tasks } \\
\text { more quickly }\end{array}$ & \\
\hline & $\mathrm{T} 2$ & The use of Cloud Computing will provide real benefits for the patients & {$[13,16]$} \\
\hline & T3 & Cloud Computing will increase the productivity of organisation's staff & \\
\hline \multirow{3}{*}{$\begin{array}{l}\text { Technology } \\
\text { readiness }\end{array}$} & $\mathrm{T} 4$ & My organisation has provided Internet access to all its members & {$[16,44]$} \\
\hline & $\mathrm{T} 5$ & $\begin{array}{l}\text { The IT infrastructure of my organisation can support the adoption of Cloud } \\
\text { Computing }\end{array}$ & {$[71]$} \\
\hline & T6 & My organisation makes good use of IT to achieve its goals & \\
\hline \multirow[t]{3}{*}{ Compatibility } & $\mathrm{T} 7$ & $\begin{array}{l}\text { Cloud Computing services will be compatible with the current business } \\
\text { strategy of my organisation }\end{array}$ & {$[44,51,68]$} \\
\hline & $\mathrm{T} 8$ & $\begin{array}{l}\text { Cloud Computing technology is compatible with the current IT infrastructure } \\
\text { (hardware/software) of my organisation }\end{array}$ & {$[13,36,74]$} \\
\hline & T9 & Cloud Computing is compatible with the healthcare values and goals & {$[69]$} \\
\hline \multirow[t]{2}{*}{$\mathrm{CIO}$ innovativeness } & H1 & My organisation usually tries to use the latest technologies & {$[13,36]$} \\
\hline & $\mathrm{H} 2$ & My organisation is open to experimenting with the latest technologies & \\
\hline \multirow[t]{2}{*}{ Internal expertise } & $\mathrm{H} 3$ & $\begin{array}{l}\text { My organisation has enough human resources with necessary skills to adopt } \\
\text { Cloud Computing services }\end{array}$ & {$[13,44]$} \\
\hline & $\mathrm{H} 4$ & $\begin{array}{l}\text { IT staff in my organisation will find it easy to learn about Cloud Computing } \\
\text { applications and platforms }\end{array}$ & \\
\hline \multirow{2}{*}{$\begin{array}{l}\text { Prior technology } \\
\text { experience }\end{array}$} & H5 & IT staff in my organisation are familiar with Cloud Computing services & {$[36,76]$} \\
\hline & H6 & $\begin{array}{l}\text { IT staff in my organisation have previous experience in Information } \\
\text { System/Information Technology project development }\end{array}$ & [13] \\
\hline \multirow[t]{2}{*}{$\begin{array}{l}\text { Top management } \\
\text { support }\end{array}$} & $\mathrm{O} 1$ & $\begin{array}{l}\text { The organisation's top management involves itself in the process when it } \\
\text { comes to IS/IT projects }\end{array}$ & {$[16,44,51]$} \\
\hline & $\mathrm{O} 2$ & $\begin{array}{l}\text { The organisation's top management supports the adoption of Cloud } \\
\text { Computing }\end{array}$ & {$[36,71,77]$} \\
\hline \multirow[t]{2}{*}{$\begin{array}{l}\text { Attitude toward } \\
\text { change }\end{array}$} & $\mathrm{O} 3$ & $\begin{array}{l}\text { The implementation of Cloud Computing will be accepted by IT staff in my } \\
\text { organisation }\end{array}$ & {$[3,73,78]$} \\
\hline & $\mathrm{O} 4$ & $\begin{array}{l}\text { The implementation of Cloud Computing will be accepted by healthcare } \\
\text { professionals in my organisation }\end{array}$ & \\
\hline \multirow[t]{3}{*}{$\begin{array}{l}\text { Regulation } \\
\text { compliance }\end{array}$} & E1 & $\begin{array}{l}\text { Government regulations in Saudi Arabia are sufficient to protect the users } \\
\text { from risks associated with Cloud Computing }\end{array}$ & {$[13,44,69]$} \\
\hline & E2 & There are Saudi laws regarding ownership and responsibility for patient data & \\
\hline & E3 & $\begin{array}{l}\text { The use of Cloud Computing allows sensitive data to be protected from } \\
\text { unauthorised people }\end{array}$ & \\
\hline \multirow{3}{*}{$\begin{array}{l}\text { Business ecosystem } \\
\text { partners pressure }\end{array}$} & E4 & Cloud Computing is recommended by the government of Saudi Arabia & {$[16,44]$} \\
\hline & E5 & $\begin{array}{l}\text { In Saudi Arabia, many healthcare organisations are currently adopting Cloud } \\
\text { Computing }\end{array}$ & {$[26,36,50]$} \\
\hline & E6 & $\begin{array}{l}\text { Using Cloud Computing will allow my organisation to easily switch its IT } \\
\text { providers }\end{array}$ & \\
\hline \multirow[t]{2}{*}{ External expertise } & E7 & $\begin{array}{l}\text { In Saudi Arabia, there are many IT providers with experience in healthcare } \\
\text { systems }\end{array}$ & {$[36,46,73]$} \\
\hline & E8 & $\begin{array}{l}\text { In Saudi Arabia, there are many IT providers with good credibility and } \\
\text { reputation }\end{array}$ & \\
\hline \multirow[t]{3}{*}{$\begin{array}{l}\text { Hard financial } \\
\text { analysis }\end{array}$} & B1 & $\begin{array}{l}\text { Cloud Computing can reduce the operating cost of information technology in } \\
\text { the healthcare organisations }\end{array}$ & {$[13,26,44]$} \\
\hline & B2 & My organisation has enough budget to develop Cloud Computing technology & \\
\hline & B3 & $\begin{array}{l}\text { The use of Cloud Computing will provide new opportunities for the } \\
\text { organisation }\end{array}$ & \\
\hline \multirow[t]{3}{*}{$\begin{array}{l}\text { Soft financial } \\
\text { analysis }\end{array}$} & B4 & $\begin{array}{l}\text { The use of Cloud Computing will allow the organisation to provide services } \\
\text { that could not be provided before }\end{array}$ & {$[8,44,79]$} \\
\hline & B5 & $\begin{array}{l}\text { The adoption of Cloud Computing will affect business processes in my } \\
\text { organisation positively }\end{array}$ & \\
\hline & B6 & Cloud Computing will affect medical services in my organisation positively & \\
\hline \multirow{5}{*}{$\begin{array}{l}\text { Cloud Computing } \\
\text { adoption }\end{array}$} & \multicolumn{2}{|c|}{ What is your organisation's plan for Cloud Computing adoption? } & [13] \\
\hline & & [44] \\
\hline & \multicolumn{2}{|c|}{ We intend to adopt Cloud Computing services in the next 2 years } & \\
\hline & \multicolumn{2}{|c|}{ We do not intend to adopt any Cloud Computing services for the foreseeable future } & \\
\hline & \multicolumn{2}{|c|}{ I do not know } & \\
\hline
\end{tabular}

All items are based on five-point scale except those noted otherwise 


\section{References}

1. Alharbi F, Atkins A, Stanier C (2015) Strategic framework for cloud computing decision-making in healthcare sector in Saudi Arabia. In: The seventh international conference on ehealth, telemedicine, and social medicine, pp 138-144

2. Khalifa M (2013) Barriers to health information systems and electronic medical records implementation. A field study of Saudi Arabian Hospitals. In: The 3rd international conference on current and future trends of information and communication technologies in healthcare (ICTH), vol 21, pp 335-342

3. Alkraiji A, Jackson T, Murray I (2013) Barriers to the widespread adoption of health data standards: an exploratory qualitative study in tertiary healthcare organizations in Saudi Arabia. J Med Syst 37(2):9895

4. Kuo AM (2011) Opportunities and challenges of cloud computing to improve health care services. J Med Internet Res 13(3):e67

5. Marston S, Li Z, Bandyopadhyay S, Zhang J, Ghalsasi A (2011) Cloud computing - the business perspective. Dec Support Syst 51(1):176-189

6. Mell P, Grance T (2011) The NIST definition of cloud computing. National Institute of Standards and Technology (U.S. Department of Commerce), USA

7. Sultan N (2014) Making use of cloud computing for healthcare provision: opportunities and challenges. Int J Inf Manag 34(2): 177 184

8. AbuKhousa E, Mohamed N, Al-Jaroodi J (2012) E-health cloud: opportunities and challenges. Future Internet 4(4):621-645

9. International Futures (IFs) forecasting system (2016) Key development forecasting-Saudi Arabia. University of Denver [Online]. http://www.ifs.du.edu/ifs/frm_CountryProfile.aspx? Country=SA. Accessed 28 Jun 2016

10. Alharbi F, Atkins A, Champion J (2014) Cloud Computing is reshaping health services in Saudi Arabia: a strategic view. In: 8th international conference on advanced computing and communication technologies, pp 172-177

11. Alkhater N, Wills G, Walters R, Wills G, Walters R (2014) Factors influencing an organisation's intention to adopt cloud computing in Saudi Arabia. In: 2014 IEEE 6th international conference on cloud computing technology and science, pp 1040-1044

12. Yamin M (2013) Cloud economy of developing countries. World J Soc Sci 3(3):132-142

13. Lian J-W, Yen DC, Wang Y-T (2014) An exploratory study to understand the critical factors affecting the decision to adopt cloud computing in Taiwan hospital. Int J Inf Manag 34(1):28-36

14. Rijnboutt E, Routsis D, Venekamp N, Fulgencio H, Rezai M, van der Helm A (2013) What challenges have to be faced when using the cloud for e-health services? In: 2013 IEEE 15th international conference on e-health networking, applications and services (Healthcom 2013), no. Healthcom, pp 465-470

15. Ho L, Atkins AS (2006) Outsourcing decision-making: a review of strategic frameworks and proposal of a multi-perspective approach. In: Kehal HS, Singh VP (eds) Outsourcing and offshoring in the 21st century. Idea Group Inc (IGI), pp 165-196

16. Low C, Chen Y, Wu M (2011) Understanding the determinants of cloud computing adoption. Ind Manag Data Syst 111(7):10061023

17. Klein CA (2011) Cloudy confidentiality: clinical and legal implications of cloud computing in health care. J Am Acad Psychiatry Law 39(4):571-578

18. Alharbi ST (2012) Users' acceptance of cloud computing in Saudi Arabia. Int J Cloud Appl Comput 2(2):1-11

19. Tashkandi AN, Al-Jabri IM (2015) Cloud computing adoption by higher education institutions in Saudi Arabia: an exploratory study. Clust Comput
20. McDougall A, Duckett P, Manku M, Robertson J (2003) International Health Comparisons

21. Liu C-F, Hwang H-G, Chang H-C (2011) E-healthcare maturity in Taiwan. Telemed J e-Health 17(7):569-573

22. MOH (2011) National e-Health Strategy [Online]. http://www.m oh.gov.sa/en/Ministry/nehs/Pages/default.aspx. Accessed 20 Sep 2014

23. Hasanain RA, Cooper H (2014) Solutions to overcome technical and social barriers to electronic health records implementation in Saudi public and private hospitals. J Health Inf Dev Ctries 8(1):4663

24. El-gazzar RF (2014) An overview of cloud computing adoption challenges in the Norwegian Context. In: IEEE/ACM 7th international conference on utility and cloud computing, pp 412-418

25. Senyo PK, Addae E, Adam IO (2015) An overview of cloud computing adoption across industries in a developing country. In: Information systems education conference, pp 322-332

26. Güner EO, Sneiders E (2014) Cloud computing adoption factors in Turkish. In: PACIS 2014 Proceedings, p 353

27. Sadoughi F, Kimiafar K, Ahmadi M, Shakeri MT (2013) Determining of factors influencing the success and failure of hospital information system and their evaluation methods: a systematic review. Iran Red Crescent Med J 15(12):e11716

28. Lluch M (2011) Healthcare professionals' organisational barriers to health information technologies-a literature review. Int J Med Inf 80(12):849-62

29. van Gemert-Pijnen JEWC, Nijland N, van Limburg M, Ossebaard HC, Kelders SM, Eysenbach G, Seydel ER (2011) A holistic framework to improve the uptake and impact of eHealth technologies. J Med Internet Res 13(4):e111

30. Sultan N, van de Bunt-Kokhuis S (2012) Organisational culture and cloud computing: coping with a disruptive innovation. Technol Anal Strat Manag 24(2):167-179

31. Tornatzky LG, Fleischer M, Chakrabarti AK (1990) Processes of technological innovation

32. Oliveira T, Martins MF (2011) Literature review of information technology adoption models at firm level. Electron J Inf Syst Eval 14(1):110-121

33. Lee C-P, Shim JP (2007) An exploratory study of radio frequency identification (RFID) adoption in the healthcare industry. Eur J Inf Syst 16(6):712-724

34. Oliveira T, Martins MFO (2008) A comparison of web site adoption in small and large Portuguese Firms. In: ICE-B, pp 370-377

35. Liu M (2008) Determinants of e-commerce development: an empirical study by firms in Shaanxi, China. In: 4th international conference on wireless communications, networking and mobile computing. IEEE, pp 1-4

36. Alshamaila Y, Papagiannidis S, Li F (2013) Cloud computing adoption by SMEs in the north east of England: a multi-perspective framework. J Enterp Inf Manag 26(3):250-275

37. Frenzel CW (1992) Management of information technology. Cengage learning

38. Schneider S, Sunyaev A (2014) Determinant factors of cloudsourcing decisions: reflecting on the IT outsourcing literature in the era of cloud computing. J Inf Technol:1-31

39. Alharbe N, Atkins AS, Akbari AS (2013) Application of ZigBee and RFID technologies in healthcare in conjunction with the internet of things. In: Proceedings of international conference on advances in mobile computing and multimedia-MoMM '13, pp 191-195

40. Ho L, Atkins A (2009) IT portfolio management: a holistic approach to outsourcing decisions. IGI Global

41. Paré G, Trudel M-C (2007) Knowledge barriers to PACS adoption and implementation in hospitals. Int J Med Inf 76(1):22-33

42. Yusof MM, Kuljis J, Papazafeiropoulou A, Stergioulas LK (2008) An evaluation framework for health information systems: human, 
organization and technology-fit factors (HOT-fit). Int J Med Inf 77(6):386-398

43. Haddad P, Gregory M, Wickramasinghe N (2014) Business value of IT in Healthcare Peter. In: Wickramasinghe N, Al-Hakim L, Gonzalez C, Tan J (eds) Lean thinking for healthcare. Springer, New York, pp 55-81

44. Oliveira T, Thomas M, Espadanal M (2014) Assessing the determinants of cloud computing adoption: an analysis of the manufacturing and services sectors. Inf Manag 51(5):497-510

45. Grobauer ESB, Walloschek T (2011) Understanding cloud computing vulnerabilities. IEEE Secur Priv 9(2):50-57

46. Nkhoma MZ, Dang DPT (2013) Contributing factors of cloud computing adoption: a technology-organisation-*environment framework approach. Int J Inf Syst Eng 1(1):38-49

47. Barakah DM, Alrobia AM, Alwakeel S (2014) Strategic plan and development projects for modern health clinical information systems at King Saud Medical City. Int J Inf Electron Eng 4(4):317321

48. Boonstra A, Broekhuis M (2010) Barriers to the acceptance of electronic medical records by physicians from systematic review to taxonomy and interventions. BMC Health Serv Res 10:231

49. Schweitzer EJ (2011) Reconciliation of the cloud computing model with US federal electronic health record regulations. J Am Med Inf Assoc 19(2):161-5

50. Hsu P-F, Ray S, Li-Hsieh Y-Y (2014) Examining cloud computing adoption intention, pricing mechanism, and deployment model. Int J Inf Manag 34(4):474-488

51. Borgman HP, Bahli B, Heier H, Schewski F (2013) Cloudrise: exploring cloud computing adoption and governance with the TOE framework. In: 2013 46th Hawaii international conference on system sciences, pp 4425-4435

52. Khudair AA (2008) Electronic health records?: Saudi physicians' perspective. In: Appropriate healthcare technologies for developing countries, pp 1-7

53. Chang HH, Chou PB, Ramakrishnan S (2009) An ecosystem approach for healthcare services cloud. In: 2009 IEEE international conference on e-business engineering, pp 608-612

54. Moore G, Benbasat I (1991) Development of an instrument to measure the perceptions of adopting an information technology innovation. Inf Syst Res 2:192-222

55. Chang V, Walters RJ, Wills G (2014) Review of cloud computing and existing frameworks for cloud adoption. In: Ramachandran M (ed) Advances in cloud computing research. Nova Science Publishers, New York

56. Alshammari H (2009) Managerial roles of the hospital managers in Saudi Arabia Research design. In: 1st international conference on health services delivery management

57. Saunders M, Lewis P, Thornhill A (2009) Research methods for business students, 5th edn. Pearson Education Limited, London

58. Singleton RA Jr, Straits BC (2009) Approaches to social research, 5th edn. Oxford University Press, Oxford

59. Van Selm M, Jankowski NW (2006) Conducting online surveys. Qual Quant 40:435-456

60. $\mathrm{MOH}$ (2012) Health statistics annual book

61. Hung S-Y, Hung W-H, Tsai C-A, Jiang S-C (2010) Critical factors of hospital adoption on CRM system: organizational and information system perspectives. Dec Support Syst 48(4):592-603
62. JA Gliem, Gliem RR (2003) Calculating, interpreting, and reporting Cronbach's Alpha reliability coefficient for Likert-Type Scales. In: 2003 Midwest research to practice conference in adult, continuing, and community education, no. 1992, pp 82-88

63. HIMSS (2014) 2014 HIMSS analytics cloud survey

64. Oredo JO, Njihia JM (2014) Mindfulness and quality of innovation in cloud computing adoption. Int J Bus Manag 10(1):144-160

65. Hsu P (2013) Cloud computing adoption in Taiwan: an eemprical sudy. In: International DSI and Asia Pacific DSI conference, pp 907-927

66. Awosan RK (2014) Factor analysis of the adoption of cloud computing in Nigeria. Afr J Comput ICT 7(1):33-42

67. Runeson P, Höst M (2009) Guidelines for conducting and reporting case study research in software engineering. Empir Softw Eng 14(2004):131-164

68. Lin A, Chen N (2012) Cloud computing as an innovation?: percepetion, attitude, and adoption. Int J Inf Manag 32(6):533-540

69. Morgan L, Kieran C (2013) Factors affecting the adoption of cloud computing?: an exploratory study. In: The 21st European conference on information systems, pp 1-12

70. Wu YUN, Cegielski CG, Hazen BT, Hall DJ (2013) Cloud computing in support of supply chain information system infrastructure: understaning when to go to the cloud. J Supply Chain Manag Exclus 49(3):25-41

71. Lumsden JRI, Anabel G (2013) Understanding the determinants of cloud computing adoption within the UK. In: European, Mediterranean and Middle Eastern conference on information systems, vol 2013, pp 1-16

72. Rosenthal A, Mork P, Li MH, Stanford J, Koester D, Reynolds P (2010) Cloud computing: a new business paradigm for biomedical information sharing. J Biomed Inf 43(2):342-53

73. Yeboah-boateng EO, Essandoh KA (2014) Factors influencing the adoption of cloud computing by small and medium enterprises in developing economies. Int J Emerg Sci Eng 2(4):13-20

74. Tan M, Tc T, Margaret L (2012) Exploring organizational adoption of cloud computing in Singapore. In: The 19th ITS Biennial conference 2012 "Moving Forward with Future Technologies?: Opening a Platform for All", pp 1-21

75. Rezaeibagha F, Win KT, Susilo W (2015) A systematic literature review on security and privacy of electronic health record systems?: technical perspectives 44(3)

76. Son I, Lee D, Lee J-N, Chang YB (2014) Market perception on cloud computing initiatives in organizations: an extended resourcebased view. Inf Manag 51(6):653-669

77. Chang B-Y, Hai PH, Seo D-W, Lee J-H, Yoon SH (2013) The determinant of adoption in cloud computing in Vietnam. In: 2013 international conference on computing, management and telecommunications (ComManTel), pp 407-409

78. Turan AH, Palvia PC (2014) Critical information technology issues in Turkish healthcare. Inf Manag 51(1):57-68

79. Chen S-H, Wen P-C, Yang C-K (2014) Business concepts of systemic service innovations in e-Healthcare. Technovation, pp 1-12 